This is the author's final, peer-reviewed manuscript as accepted for publication. The publisher-formatted version may be available through the publisher's web site or your institution's library.

\title{
A multivariable assessment quantifying effects of cohort- level factors associated with combined mortality and culling risk in cohorts of U.S. commercial feedlot cattle
}

A. H. Babcock, N. Cernicchiaro, B. J. White, S. R. Dubnicka, D. U. Thomson, S. E. Ives, H. M. Scott, G. A. Milliken, D. G. Renter

\section{How to cite this manuscript}

If you make reference to this version of the manuscript, use the following information:

Babcock, A. H., Cernicchiaro, N., White, B. J., Dubnicka, S. R., Thomson, D. U., Ives, S. E., . . Renter, D. G. (2013). A multivariable assessment quantifying effects of cohortlevel factors associated with combined mortality and culling risk in cohorts of U.S. commercial feedlot cattle. Retrieved from http://krex.ksu.edu

\section{Published Version Information}

Citation: Babcock, A. H., Cernicchiaro, N., White, B. J., Dubnicka, S. R., Thomson, D. U., Ives, S. E., . . Renter, D. G. (2013). A multivariable assessment quantifying effects of cohort-level factors associated with combined mortality and culling risk in cohorts of U.S. commercial feedlot cattle. Preventive Veterinary Medicine, 108(1), 38-46.

Copyright: @ 2012 Elsevier B.V.

Digital Object Identifier (DOI): doi:10.1016/j.prevetmed.2012.07.008

Publisher's Link: http://www.sciencedirect.com/science/article/pii/S0167587712002334

This item was retrieved from the K-State Research Exchange (K-REx), the institutional repository of Kansas State University. K-REx is available at http://krex.ksu.edu 


\section{A multivariable assessment quantifying effects of cohort-level factors associated with}

2 combined mortality and culling risk in cohorts of U.S. commercial feedlot cattle

3 A.H. Babcock ${ }^{\mathrm{a}}$, N. Cernicchiaro ${ }^{\mathrm{a}}$, B.J. White ${ }^{\mathrm{b}}$, S.R. Dubnicka ${ }^{\mathrm{c}}$, D.U. Thomson ${ }^{\mathrm{b}}$, S.E. Ives ${ }^{\mathrm{d}}$, H.M.

4 Scott $^{\mathrm{a}}$, G.A. Milliken ${ }^{\mathrm{c}}$, D.G. Renter ${ }^{\mathrm{a}, *}$

5

$6 \quad{ }^{a}$ Department of Diagnostic Medicine and Pathobiology, College of Veterinary Medicine, Kansas

7 State University, Manhattan, Kansas, United States

$8 \quad{ }^{\mathrm{b}}$ Department of Clinical Sciences, College of Veterinary Medicine, Kansas State University,

$9 \quad$ Manhattan, Kansas, United States

$10{ }^{\mathrm{c}}$ Department of Statistics, College of Arts and Sciences, Kansas State University, Manhattan,

11 Kansas, United States

$12{ }^{\mathrm{d}}$ Cactus Operating, LLC., Cactus, Texas, United States

$21{ }^{*}$ Corresponding author. Present address: 307 Coles Hall, Department of Diagnostic Medicine and

22 Pathobiology, Kansas State University, Manhattan, KS 66506, USA. Tel.: +1-785-532-4801;

23 fax: +1-785-532-4851. E-mail address: drenter@vet.ksu.edu (D.G. Renter). 


\section{Abstract}

25 Economic losses due to cattle mortality and culling have a substantial impact on the feedlot

26 industry. Since criteria for culling may vary and may affect measures of cumulative mortality

27 within cattle cohorts, it is important to assess both mortality and culling when evaluating cattle

28 losses over time and among feedlots. To date, there are no published multivariable assessments

29 of factors associated with combined mortality and culling risk. Our objective was to evaluate

30 combined mortality and culling losses in feedlot cattle cohorts and quantify effects of commonly

31 measured cohort-level risk factors (weight at feedlot arrival, gender, and month of feedlot

32 arrival) using data routinely collected by commercial feedlots. We used retrospective data

33 representing 8,904,965 animals in 54,416 cohorts from 16 U.S. feedlots from 2000 to 2007. The

34 sum of mortality and culling counts for each cohort (given the number of cattle at risk) was used

35 to generate the outcome of interest, the cumulative incidence of combined mortality and culling.

36 Associations between this outcome variable and cohort-level risk factors were evaluated using a

37 mixed effects multivariable negative binomial regression model with random effects for feedlot,

38 year, month and week of arrival. Mean arrival weight of the cohort, gender, and arrival month

39 and a three-way interaction (and corresponding two-way interactions) between arrival weight,

40 gender and month were significantly $(P<0.05)$ associated with the outcome. Results showed

41 that as the mean arrival weight of the cohort increased, mortality and culling risk decreased, but

42 effects of arrival weight were modified both by the gender of the cohort and the month of feedlot

43 arrival. There was a seasonal pattern in combined mortality and culling risk for light and middle-

44 weight male and female cohorts, with a significantly $(P<0.05)$ higher risk for cattle arriving at

45 the feedlot in spring and summer (March through September) than in cattle arriving during fall,

46 and winter months (November through February). Our results quantified effects of covariate 
47 patterns that have been heretofore difficult to fully evaluate in smaller scale studies; in addition,

48 they illustrated the importance of utilizing multivariable approaches when quantifying risk

49 factors in heterogeneous feedlot populations. Estimated effects from our model could be useful

50 for managing financial risks associated with adverse health events based on data that are

51 routinely available.

52

53 Keywords: cattle, culling, mortality, negative binomial regression, risk factors

54

55

56

57

58

59

60

61

62

63

64

65

66

67 


\section{Introduction}

Losses due to cattle mortality and culling have tremendous economic impacts on North American feedlot production systems (Smith et al., 2001). These economic impacts reflect costs

71 associated with feed consumption, personnel labor, pharmaceutical products, carcass disposal,

72 price paid for the animal, and loss of interest on invested money. Despite continued advances in

73 health management programs and pharmaceutical products, recent research indicates that U.S.

74 feedlot mortality risk has increased over time (Loneragan et al., 2001; Loneragan, 2004; Babcock

75 et al., 2006). However, the apparent increased risk over time may be due to true increases in

76 mortality across feedlot populations, changes in cattle demographics and corresponding risk

77 factors, or an increasing reluctance of feedlots to cull cattle. Culling is defined as removal of

78 animals from their cohort prior to harvest. Feedlots may have different criteria on culling

79 chronically ill or poor performing animals prior to harvest, and may cull animals in an attempt to

80 decrease overall mortality. If feedlot personnel cull animals quickly and aggressively, the

81 mortality risk for the population may appear low relative to similar populations of cattle in

82 feedlots with more conservative culling practices. Some researchers have suggested that a more

83 comprehensive approach to assessing cattle losses across multiple feedlots and years would

84 require that data on mortality and culling are combined and assessed simultaneously using

85 multivariable models accounting for differences in cattle populations (Loneragan, 2004). Multivariable approaches assessing risk factors for mortality and culling are important

87 because cattle demographics changing over time, within and across feedlots, can confound the 88 observed relationship between seasonal patterns and health risks (Ribble et al., 1995). Literature 89 quantifying effects of risk factors of feedlot mortality are limited, and there are no published data 90 on factors affecting culling of feedlot cattle. Animal weight at feedlot arrival, gender, arrival 
91 month, weather, and commingling of cattle have been found to be associated with feedlot

92 mortality risk (Martin et al., 1982; MacVean et al., 1986; Ribble et al., 1998; Loneragan, 2004).

93 However, most studies of mortality risks have used data from only a limited number of feedlots,

94 or used data aggregated by month at the feedlot level; when cohort should be the unit of interest

95 as feedlots tend to purchase, manage and market cattle as cohorts (often called "lots" of cattle).

96 There are no published data demonstrating the effects of multiple risk factors and their

97 interactions on combined mortality and culling risk in cohorts of commercial feedlot cattle.

98 Quantifying the effects of potential risk factors will allow managers of feedlot finances and cattle

99 health to make more informed production decisions about cattle cohorts they typically purchase,

100 and also provide data on atypical cohorts where the effects of risk factors are often difficult to

101 quantify due to a lack of data. The objective of our study was to quantify the effects of

102 commonly measured cohort-level risk factors on combined cumulative mortality and culling risk

103 within cattle cohorts using operational data routinely collected by commercial feedlots.

104

105 2. Materials and Methods

106 2.1. Data

107

We collected cohort-level data from commercial feedlots in four U.S. states (Colorado,

108 Kansas, Nebraska, and Texas). Cohorts were considered as "lots" of animals that may or may

109 not have been housed in the same physical location (pen) for the duration of the feeding period;

110 however, all animals in a lot were purchased, managed and marketed similarly. Cohort-level

111 variables regularly collected across feedlots were: mean weight on arrival at the feedlot

112 (recorded on an interval scale), days on feed (recorded on a continuous scale), gender and arrival

113 date (recorded on a nominal scale). Cattle were designated as male or female in our analysis, 
114 rather than steer or heifer, as data on the castration or pregnancy status on arrival to the feedlot

115 were not consistently available. Data on several other potential risk factors were either not

116 existent or were not collected consistently across feedlots; therefore, additional variables (e.g.,

117 shipping distance, source location, preconditioning) were not incorporated in the analysis. Study

118 inclusion criteria included: feedlots that reported cohort-level data on both mortality and culling,

119 cohorts classified as male or female (not mixed) that arrived to the feedlot between 2000 and

120 2007, and cohorts containing between 40 and 340 animals upon arrival with a mean arrival

121 weight between 91 and $470 \mathrm{~kg}$. The sum of mortality and culling counts for each cohort (given

122 the number of cattle at risk) was used to generate the outcome of interest, hereafter referred as

123 the combined mortality and culling risk, representing the cumulative incidence over each

124 cohort’s feeding period.

125

\section{2.2. Regression model}

127 Associations between cohort-level demographic factors with the incidence risk of the

128 combined mortality and culling were modeled using a generalized linear mixed model (Proc

129 GLIMMIX) built in SAS 9.2 (SAS Institute Inc., Cary, NC, USA), with a negative binomial

130 distribution, log link function, and maximum likelihood estimation based on Laplace

131 approximation of the marginal log likelihood. The count of combined mortality and culling

132 within each cohort was the outcome of interest and the natural logarithm of the total number of

133 cattle within each cohort upon feedlot arrival (considered our population at risk) was specified as

134 the offset variable of the model. To account for the hierarchical structure of the data, a cross-

135 classification of feedlot-years (11 feedlots in 2000, 13 in 2001-2002, 14 in 2003, and 16 in 2004-

136 2007) was included as a random intercept to model the overdispersion arising from the lack of 
137 independence of cohorts nested within feedlots, and of feedlots nested within arrival years. In

138 addition, arrival month $(\mathrm{n}=12)$ was modeled as a random intercept using a first-order

139 autoregressive covariance structure to account for the repeated measures of cohorts, within

140 feedlot-years, over months with decay in correlation with increasing distance between

141 observations (Dohoo et al., 2009). Lastly, arrival week $(n=5)$ within a month was modeled as a

142 random intercept to control for the correlation of weeks within arrival months.

143 Independent variables tested in our regression models, which were also the main

144 predictors of interest based on our causal models, included: mean arrival weight of the cohort,

145 gender of the cohort, and arrival month. The linearity assumption between the log of the

146 expected value of the incidence risk of the outcome and mean cohort arrival weight, originally

147 recorded on a continuous scale, was not met. Thus, this variable was categorized into $22.7 \mathrm{~kg}$

148 (approximately $50 \mathrm{lbs}$, cutoff commonly used in the feedlot industry) categories using Walter's

149 hierarchical methods to categorize ordinal independent variables (Walter et al., 1987). A

150 backward elimination procedure (with $P<0.05$ ) was used to collapse arrival weight categories

151 inward toward the initially centered referent category (i.e., 295 to $317 \mathrm{~kg}$, category that

152 represented the most frequent cohort arrival weight). This process resulted in the following nine

153 weight categories: <182, 182 to 204, 205 to 227, 228 to 249, 250 to 271, 272 to 317, 318 to 340 ,

154341 to 362 and $>362 \mathrm{~kg}$. Gender of the cohort (male vs. female) and arrival month (January

155 through December) were analyzed on a nominal scale as initially recorded by the feedlots.

156 Variables pertaining to the length of the feeding period or days on feed and cohort size were

157 considered intervening variables in our causal model, as they may intervene in the causal

158 pathway between arrival weight class, arrival month, gender and the predicted outcome, 
159 respectively. Thus, these variables were not included in the final model as they would prevent us

160 from correctly estimating the true effects of the main predictors of interest (Dohoo et al., 2009).

161 A pair-wise correlation analysis was performed using the Spearman's rank correlation

162 statistic to identify possible collinearity among independent variables. If the value of the

163 correlation statistic was $|0.8|$ or higher, one of the variables was selected to be included into the

164 multivariable model based upon completeness and quality of the available data (Dohoo et al., 165 2009).

After conducting bivariable analyses assessing the association between the combined

167 mortality and culling risk with each independent variable, a mixed-effects multivariable main

168 effects model was built by including variables significantly associated to the outcome at the $5 \%$

169 significance level $(P<0.05)$, using a manual backward elimination procedure.

170 A three-way interaction (and its corresponding two-way interactions) among arrival

171 weight, gender, and arrival month, was tested $(P<0.05)$ using a backward elimination

172 procedure. Significance testing for all stages of model building was performed using likelihood-

173 ratio tests comparing the full to the reduced model for the categorical predictors included in our

174 model (Dohoo et al., 2009).

175 Diagnostic assessment of residuals from the final multivariable model included the

176 evaluation of the predicted values of the random variables in the model or best linear unbiased

177 predictors (BLUPs) for the feedlot by year combinations. Predicted relative risk (RR) of

178 combined mortality and culling risks based on analysis of 54,410 cohorts of commercial feedlot

179 cattle were computed. The BLUPs are of the form of a feedlot by year combination mean minus

180 the overall mean, as: $\bar{y}_{\ldots \text {.. mn .. }}-\bar{y}_{\text {........ }}$ where $\bar{y}_{\text {...mnn.. }}$ denotes the mean of the $\mathrm{m}^{\text {th }}$ arrival year at 


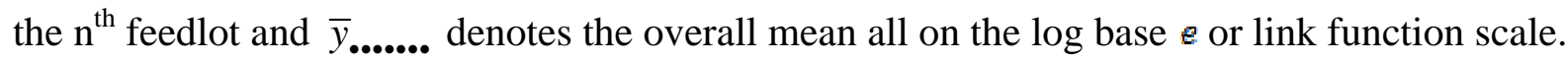

182 The inverse link of these predictors provides the following:

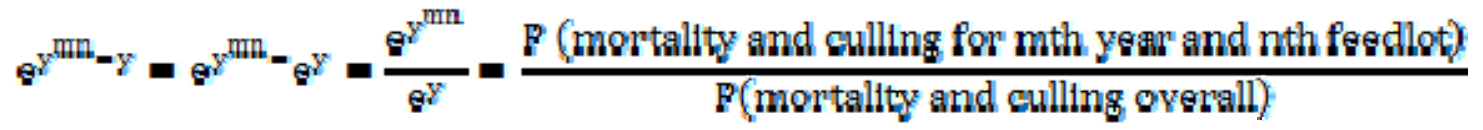

- Relative Risk (RR) at nth feedlot in the mth year as compared to the overall average.

Normal probability plots, Kolmogorov-Smirnov, Cramer-von Mises, and Anderson-Darling tests

186 for normality were examined to assess the normality assumption of the BLUPs and general

187 model fit. Graphical indication of departures from normality or statistically significant normality

188 statistics $(P<0.05)$ were used as criteria to indicate lack of fit. To assess the pattern of combined

189 mortality and culling risk over time across feedlots, estimates of the BLUPs were plotted across

190 feedlots and arrival years based on the results of the final multivariable model. Residuals plots at

191 the lowest level (i.e., cohort) were also visually examined to assess overall model fit and to

192 identify potential outliers and influential observations. After verifying that no recording errors

193 were made, observations from cohorts with a probability of combined mortality and culling risk

194 equal or higher than 85\% $(n=10)$ were censored given their removal improved model fit and

195 convergence. Least square means and differences in model-adjusted means were estimated for

196 variables included in significant interactions in the final multivariable model.

197 When building the mixed effects multivariable model, different distributions for count

198 data (e.g., negative binomial, Poisson (Figure 1), binomial), random effects and covariance

199 pattern models were attempted, including the use of days within a week as random intercept, and

200 of sine and cosine functions to model arrival day, week and month. The best fitting model for

201 dealing with the hierarchical structure of the data was chosen based on information criteria 
202 (Akaike and Bayesian information criteria), the results of the generalized Chi-square statistic 203 divided by its degrees of freedom, and appropriate model convergence.

204

\section{3. Results}

\subsection{Descriptive statistics}

A total of 54,406 cohorts (representing 8,904,965 individual animals) from 16 different 208 feedlots during arrival years 2000 to 2007 were included in the final multivariable model. The 209 participating feedlots were located in Colorado, Kansas, Nebraska, and Texas, and their 210 capacities ranged from 22,000 to 82,000 cattle. The mean number of cattle within cohorts was

$211163(\mathrm{SE}=0.32)$ with a median of 150 animals. Sixty-four percent of the cohorts were classified 212 as male and 36\% as female. Cohort-level mean cattle arrival weight ranged from 119 to $468 \mathrm{~kg}$, 213 with a median of $322 \mathrm{~kg}$ and mean of $316 \mathrm{~kg}(\mathrm{SE}=0.24)$. Cumulative mortality risk ranged 214 from $0 \%$ to $31.9 \%$ with a median of $0.9 \%$ and mean of $1.5 \%$ ( $\mathrm{SE}=0.009 \%)$. Culling risk ranged 215 from $0 \%$ to $100 \%$, with a median of $0.9 \%$ and a mean of $0.8 \%$ (SE $=0.007 \%)$. The combined 216 mortality and culling risk ranged from $0 \%$ to $100 \%$, with a median of $1.4 \%$ and mean of $2.3 \%$ 217 (SE $=0.43 \%)$. The mean ratio of mortalities to culls across feedlots (all years) ranged from 1.3 218 to 5.1, with a median of 2.0 and a mean of 2.3 ( $\mathrm{SE}=0.004)$; among different years (all feedlots) 219 these ratios ranged from 1.2 to 3.2 with a median of 2.0 and mean of $2.1(\mathrm{SE}=0.003)$.

\subsection{Regression model}

222 The final multivariable model for combined mortality and culling risk included the 223 following significant $(P<0.05)$ predictors: gender of the cohort, arrival month, mean arrival 224 weight class, and a three-way interaction (and corresponding two-way interactions) among the 
225 three main effects (parameter estimates are available upon request to the corresponding author).

226 The effect of the cohort's gender on combined mortality and morbidity risk depended on the

227 weight class and the month of feedlot arrival. Figures 2 and 3, and Tables 1 and 2, depict the

228 model-estimated probabilities of mortality and culling risk for the arrival weight groups for each

229 arrival month by gender. Generally the lower arrival weight calves had higher probabilities of

230 combined mortality and culling risk. Similar patterns are shown to exist for both males and

231 females: as arrival weight increased, combined mortality and culling risk decreased. For males,

232 light weight cattle $(<182 \mathrm{~kg})$ showed a significantly $(P<0.05)$ higher risk of mortality and

233 culling risk in March to April, June to July and October to November, with the highest peak

234 occurring in August (Figure 2, Table 1). In middleweight classes (182 to $271 \mathrm{~kg}$ ), the combined

235 mortality and culling risk mainly increased in the months of May to June to then stabilize and

236 decreased towards December. Heavier weight males ( $>271 \mathrm{~kg}$ ) showed a constant lower

237 mortality and culling risk compared to their lighter weight counterparts (Figure 2, Table 1).

238 Females showed a similar pattern compared to males as lighter weight cattle had significantly ( $P$

$239<0.05$ ) higher risk of mortality and culling than heavier cattle, across the different arrival

240 months. Light weight females ( $<182 \mathrm{~kg}$ ) showed higher cumulative mortality and culling risk

241 earlier in the months of March and May, recording the highest peak in risk from August to

242 October (Figure 3, Table 2). Middleweight female cattle cohorts (182 to $271 \mathrm{~kg}$ ) showed a steady

243 increment of mortality and culling risk from March to September to then decrease in the months

244 of November and December, whereas heavier weight females (>271 kg) showed a constant lower

245 risk of mortality and culling than females in lighter weight categories (Figure 3, Table 2).

246 Visual appraisal of the plotted final model's best linear unbiased predictors (BLUPs) over

247 time across feedlots indicated that the combined mortality and culling risks were similar among 
and within years for most of the feedlots (Figure 4). However, there were a few exceptions. Two

249 feedlots (feedlots 16 and 17) had higher combined mortality and culling risks in years 2003 and

250 2007, respectively, than they had in other years or than other feedlots had in 2003 and 2007

251 (Figure 4). In addition, feedlots 41 and 42 had lower predictions for years 2004 to 2007 than did

252 other feedlots during those years (Figure 4).

253 Our initial study population consisted of 54,416 cohorts, however, based on a visual

254 assessment of residual plots, ten cohorts were deemed to act as outliers in the outcome variable.

255 These cohorts, originated from four feedlots, exhibited values of probability of combined

256 mortality and culling risk that exceeded 85\%. The outliers had the following characteristics in

257 terms of covariates: cohorts arrived in years $2000(n=1), 2002(n=2), 2003(n=4), 2004(n=$

258 2) and $2006(\mathrm{n}=1)$; two were female and eight were male cohorts; and they belonged to the

259 following weight classes: <182 kg ( $\mathrm{n}=3), 182$ to $204(\mathrm{n}=1), 205$ to $227(\mathrm{n}=1), 228$ to 249 (n

$260=1), 318$ to $340(\mathrm{n}=1), 341$ to $362(\mathrm{n}=1)$ and $>362 \mathrm{~kg}(\mathrm{n}=2)$. These cohorts showed a range

261 of combined mortality and culling risk of 94.7 to $100 \%$ which was mainly driven by high culling

262 percentages (range: 91.2 to $100 \%$ ), as mortality ranged from 0 to $6.3 \%$ on this subset of cohorts.

263 In addition, our feedlot collaborators indicated that these extremely high levels of culling are

264 likely indicative of cohorts removed from the feedlot for alternative management (e.g.,

265 temporary pasture rearing) rather than true culling for health reasons. The identified outliers were

266 deleted because their removal dramatically improved the fit and convergence of the model.

268 4. Discussion

Although mortality risks for feedlot cattle have been discussed previously (Kelly and

270 Janzen, 1986; Vogel and Parrott, 1994; Loneragan, 2004), ours is the first study to use 
271 multivariable methods to quantify the effects of common risk factors and to assess the

272 combination of culling and mortality in large, commercial feedlot cattle populations. A

273 multivariable assessment of risk factors for combined mortality and culling provides a more

274 comprehensive approach to assess losses from heterogeneous populations of cattle, across

275 multiple feedlots and time (Loneragan, 2004).

276 Previous research on mortality risks was performed using only one or a limited number of

277 feedlots, or data aggregated by feedlot on a monthly basis (MacVean et al., 1986; Ribble et al.,

278 1998; Loneragan et al., 2001). Using a limited number of feedlots for analysis reduces the

279 external validity of results because feedlots may differ in terms of management, cattle

280 demographics, environmental and pathogen-related factors. Although our study population was

281 not chosen randomly, we did utilize several years of data from multiple feedlots that were similar

282 to other commercial operations in the studied U.S. region. When data aggregated at the feedlot

283 level are analyzed, important information regarding cohorts within feedlots is lost. Thus, it is not

284 possible to quantify the effects of risk factors at the cohort-level; the level at which feedlot

285 managers often make procurement, marketing and health management decisions. The structure

286 of our data enabled us to perform an analysis at the cohort-level and to utilize multivariable

287 approaches to quantify the effects of cohort-level risk factors and interactions among them that

288 have not been previously described.

289 The mean mortality $(1.5 \%)$ and $(0.8 \%)$ culling risks in our data were similar to earlier

290 reports that utilized feedlot data from the United States Department of Agriculture’s National

291 Animal Health Monitoring System (USDA, NAHMS), where mean mortality risk was reported

292 at $1.26 \%$ and mean culling risk ranged from $0.07 \%$ to $0.42 \%$ (Frank et al., 1988; Loneragan et

293 al., 2001). Others have stated that mortality risk can reach as high as five percent when freshly 
294 weaned animals six to eight months of age enter the feedlot (Smith et al., 2001). Our data

295 indicate that cumulative mortality and culling are occasionally higher than five percent: 6.2\% (n

$296=3,390$ cohorts) and $2.4 \%(n=1,301)$ of cohorts in our study population had mortality and

297 culling risks (respectively) equal or higher than 5\%.

Utilizing a large dataset containing cumulative cohort data was useful for estimating

299 cumulative measures of adverse health outcomes and assessing corresponding cohort-level risk

300 factors. However, there are also limitations to analyzing this type of data. In our study, we were

301 not able to assess the timing at which death or culling occurred. Previously, Babcock and

302 colleagues demonstrated that the timing of adverse health events affects cattle performance and

303 subsequent health measures (Babcock et al., 2009). The timing of losses due to mortality and

304 culling may have a large impact on feed and production costs; thus, temporal effects should be

305 assessed in future research. Other limitations of utilizing operational retrospective data from

306 multiple feedlot production systems pertain to the lack of consistent, standardized reporting of

307 data across feedlots (Corbin and Griffin, 2006) and to the restriction on the inferences that can be

308 made. We found only five cohort-level variables (gender, arrival weight, date of arrival, days on

309 feed and cohort size) were collected across all 16 feedlots. Therefore, we could not evaluate

310 other factors that have been assessed in smaller-scale studies, such as the origin of animals or the

311 feedlots’ feed rations (Martin et al., 1982; Ribble et al., 1995). Furthermore, we did not have data

312 available on management practices related to cattle handling and commingling during

313 transportation, which are factors that have been associated with increased risk of morbidity and

314 mortality in beef calves (Grandin, 1997; Ribble et al., 1998; Swanson and Morrow-Tesch, 2001;

315 Fike and Spire, 2006; White et al., 2009). Moreover, the distance cattle were shipped has been

316 found to be positively associated with BRD morbidity (Sanderson et al., 2008). Similarly, 
317 distance traveled was found to be a significant predictor of BRD morbidity and overall mortality

318 risks in another study; however, effects depended on specific characteristics of the cohort (region

319 the cattle originated from, cohort gender, cohort mean arrival weight and the season cattle

320 arrived at the feedlot) (Cernicchiaro et al., 2012). Unfortunately, data on the distance traveled

321 and the source of origin of these cohorts were not available in our database. These and other

322 factors could act as confounders of some of the associations reported here, and could elucidate

323 some of the unexplained variance of the presented model, as these factors can be associated with

324 demographic factors and the risk of morbidity and mortality in commercial feedlots. Lastly, the

325 retrospective, observational cross-sectional nature of the data analyzed, prevented us from

326 drawing direct causal inferences between the cohort-level demographic factors and combined

327 mortality and culling risk. Nevertheless, these data reflect the type of operational information

328 available in most feedlot operations.

329 Researchers have previously reported that feedlot mortality risks increased over time

330 during the late 1990’s and early 2000’s (Loneragan et al., 2001; Loneragan, 2004; Babcock et al.,

331 2006). The 2006 study by Babcock and colleagues showed an increasing trend in mortality risk

332 from 1992 through 2006. The results of our current study indicate that despite differences in few

333 individual feedlots, the combined mortality and culling risks for the majority of feedlots were

334 similar within and across years and feedlots after adjusting for cohort demographic variables.

335 Our results may have differed because their earlier study used data aggregated across feedlots

336 and arrival months. In addition, their data arose from a relatively small subpopulation of feedlots

$337(\mathrm{n}=9)$ located in a single geographic location in Kansas (Babcock et al., 2006).

$338 \quad$ Feedlot mortality has been assessed in several studies, but both mortality and culling

339 within cohorts have yet to be incorporated into a single outcome. In our dataset, the ratios of 
340 mortality and culling within cohorts illustrate the variability in these measures among different

341 feedlots over multiple years. Combining culling and mortality data in a single outcome can result

342 in a more precise estimate of animal losses in feedlots when comparing health performance

343 across feedlots over time (Loneragan, 2004), as well as it may provide results that are more

344 robust to differential and non-static culling criteria. However, we were unable to determine

345 whether certain risk factors have different effects across culling and mortality as separate

346 outcomes. Thus, a competing risk analysis could be used to further assess how factors affect

347 mortality and culling as two competing risks (Chiang, 1991). However, the complexity of our

348 dataset precludes standard approaches to competing risks analysis and there are very practical

349 reasons to assess effects associated with combined mortality and culling risks.

350 Our data indicated that the gender of the cohort, the mean arrival weight class and the

351 month of arrival at the feedlot were significantly associated with the combined mortality and

352 culling risk and that the effect of each predictor depended on one another. Previous research

353 determined that female cohorts have higher mortality risk than male cohorts (Loneragan et al.,

354 2001). We observed similar results in bivariable models, however, after accounting for other

355 covariates in the model, we found that the effect of gender on the combined mortality and culling

356 risk depended on weight and month at feedlot arrival, as depicted by a significant $(P<0.05)$

357 three-way interaction. The data indicated there was a seasonal pattern to the combined mortality

358 and culling risk for light and middleweight male and female cohorts, with a significantly higher

359 risk in spring and summer arrivals compared to that of cattle arriving in autumn and winter

360 months. The specific reasons for this effect modification cannot be determined in our study, but

361 there are several feedlot management practices that differ between genders, weight categories

362 and time of the year. Some factors that may explain the differences in risks between genders are 
363 related to differential hormonal status and biological processes (e.g., riding behavior of females,

364 parturition or induced abortion upon feedlot arrival), differences in steroid growth promoters and

365 rations, or differences in how female and male cattle are marketed from the cow-calf herd to the

366 feedlot (Lechtenberg et al., 1998; Smith et al., 2001).

367 Arrival weight and month are two common risk factors that are often difficult to separate

368 due to the seasonal marketing patterns of feeder cattle in North America (Ribble et al., 1995).

369 Often light weight cattle (frequently newly weaned animals) arrive at the feedlot in the autumn

370 while heavier weight (yearling animals) cattle arrive during the spring months. Differential

371 mortality and culling risk among cattle in different weight categories across different months

372 may be the result of differences in cattle types, weather characteristics, management practices in

373 different seasons, pathogen factors, or inherent physiologic and immunologic differences of

374 cattle in different weight classes. Likewise, the age of the animals on arrival may explain some

375 of those differences. Weight is often used as a proxy for age; however, animals arriving at

376 similar weights throughout the year may not always be the same age. External factors such as

377 drought or feed costs may impact the age at which cow-calf operations market and send calves to

378 feedlots (Neville and McCormick, 1981). This may also explain the high variability in risk that

379 we observed across arrival months for lighter weight cohorts.

$380 \quad$ Several weather factors (e.g., wind speed, wind chill temperature, and temperature

381 change) have been associated with increased daily incidence of respiratory disease, and their

382 effects depended on cattle demographic factors including the weight class of the cohort

383 (Cernicchiaro et al., 2011). Thus, weather effects on morbidity could have contributed the

384 subsequent higher mortality and culling risk during spring and summer months among light and

385 middleweight arriving cohorts in our study. Literature on the effects of weather on morbidity and 
mortality, particularly related to respiratory disease in feedlot cattle, is limited, yet seems to

387 indicate colder months are associated with adverse health outcomes. However, we cannot

388 dismiss the effects of hot weather adversely affecting health and performance of vulnerable cattle

389 during prolonged extreme heat (Hahn and Mader, 1997; Hahn, 1999). Further, it is plausible that

390 both colder weather in northern parts of North America and warmer weather in more southern

391 parts of the continent adversely affect cattle reared in feedlot settings. There is a need for more

392 research on the effects of management or environment conditions that impact adverse feedlot

393 cattle health. Understanding these relationships may lead to the development of better

394 management or purchasing practices for different types of cattle throughout the year.

396 and structure of the data. Initially, an examination of different functional forms of count models

397 (i.e., Poisson, negative binomial) was made (Figure 1) and compared with binomial models. The

398 negative binomial regression model was deemed to better fit these data. Although feedlots and

399 arrival years were not randomly selected in our study, they were included as random intercepts,

400 because we were interested in making inferences to wider populations of feedlots across time.

401 Smaller time units also were included as random effects (i.e., months and weeks within months)

402 to obtain a further decomposition of the variance. Moreover, a first order autoregressive structure

403 was included to model the existing autocorrelation among months. Continuing with efforts

404 directed towards improvement of the model, ten cohorts identified as outliers were removed

405 before fitting the final model. Although we recognize this approach can decrease the validity of

406 the model to predict future observations (Dohoo et al., 2009), we opted for removing these

407 observations favoring a more stable model. A future evaluation of similar datasets using 
408 Bayesian techniques or another statistical framework for complex random effects and covariance

409 structures may be appropriate.

\section{5. Conclusion}

412 Cohort-level factors associated with combined mortality and culling risk in feedlot cattle

413 can be quantified utilizing mixed models and cumulative data commonly available in the feedlot

414 industry. Interactions among effects, such as arrival month and arrival weight, have been

415 discussed anecdotally in the literature, but have never been quantified for multiple cattle types

416 and production settings. The observed effect modification and potential for confounding in these

417 data illustrate the importance of multivariable approaches when evaluating data from diverse

418 feedlot cattle populations. By demonstrating effects of factors that have not been appropriately

419 quantified in previous literature, we provide information that may be used in monitoring adverse

420 cattle health outcomes over time and among production systems, and may allow risk managers to

421 better predict potential losses for heterogeneous cattle populations by utilizing available data.

422

\section{6. Acknowledgments}

424 Funding for this study was provided by the Agriculture and Food Research Initiative of 425 the United States Department of Agriculture, National Institute of Food and Agriculture, Grant \# 426 2007-35204-18320; Contribution \# 11-395-J from the Kansas Agricultural Experiment Station, 427 Manhattan, KS. We would also like to thank the participating feedlots and their consulting 428 veterinarians for supporting this research. 
430 Babcock, A.H., Jones, R., Langemeier, M., 2006. Examining death loss in Kansas feedlots. Beef

431 Cattle Research Report of Progress. Kansas State University, Manhattan, KS, pp. 46-52.

432 Babcock, A.H., White, B.J., Dritz, S.S., Thomson, D.U., Renter, D.G., 2009. Feedlot health and 433 performance effects associated with the timing of respiratory disease treatment. J. Anim. Sci. 87, $434 \quad 314-327$.

435 Cernicchiaro, N., Renter, D.G., White, B.J., Babcock, A.H., Fox, J.T., 2011. Associations

436 between weather conditions during the first 45 days following feedlot arrival and daily

437 respiratory disease risks in autumn-placed U.S. feeder cattle. J. Anim. Sci. 90, 1328-1337.

438 Cernicchiaro, N., White, B.J., Renter, D.G., Babcock, A.H., Kelly, L., Slattery, R. 2012.

439 Associations between the distance traveled from sale barns to commercial feedlots in the United

440 States and overall performance, risk of respiratory disease, and cumulative mortality in feeder

441 cattle during 1997 to 2009. J. Anim. Sci. 90, 1929-1939.

442 Chiang, C.L. 1991. Competing risks in mortality analysis. Annu. Rev. Publ. Health 12, 281:307.

443 Corbin, M.J., Griffin, D., 2006. Assessing performance of feedlot operations using

444 epidemiology. Vet. Clin. N. Am. Food Anim. Pract. 22, 35-51.

445 Dohoo, I., Martin, W., Stryhm, H., 2009. Veterinary Epidemiologic Research. AVC Inc.,

446 Charlottetown, Prince Edward Island.

447 Fike, K., Spire, M.F. 2006. Transportation of cattle. Vet. Clin. North Am. Food Anim. Pract. 22, $448 \quad 305-320$.

449 Frank, G.R., Salman, M.D., MacVean, D.W., 1988. Use of a disease reporting system in a large 450 beef feedlot. J. Am. Vet. Med. Assoc. 192, 1063-1067.

451 Grandin, T. 1997. Assessment of stress during handling and transport. J. Anim. Sci. 75, 249-257. 
452 Hahn, G.L., Mader, T.L., 1997. Heat waves in relation to thermoregulation, feeding behavior and 453 mortality of feedlot cattle. In: Proc. 5th Intl. Livest. Environ. Symp. (Vol I). ASAESP-01-97.

454 American Society Agricultural Engineers, St. Joseph, MI., pp 563-571.

455 Hahn, G.L., 1999. Dynamic responses of cattle to thermal heat loads. J. Anim. Sci. 77, 10-20.

456 Kelly, A.P., Janzen, E.D., 1986. A review of morbidity and mortality rates and disease

457 occurrence in North American feedlot cattle. Can. Vet. J. 27, 496-500.

458 Lechtenberg, K. F., Smith, R. A., Stokka, G. L., 1998. Feedlot health and management. Vet.

459 Clin. North Am. Food Anim. Pract. 14, 177-197.

460 Loneragan, G.H., 2004. Feedlot mortalities: epidemiology, trends, classification. In, Academy of 461 Veterinary Consultants Summer Meeting. 32, 34-43.

462 Loneragan, G.H., Dargatz, D.A., Morley, P.S., Smith, M.A., 2001. Trends in mortality ratios 463 among cattle in US feedlots. J. Am. Vet. Med. Assoc. 219, 1122-1127.

464 MacVean, D.W., Franzen, D.K., Keefe, T.J., Bennett, B.W., 1986. Airborne particle

465 concentration and meteorologic conditions associated with pneumonia incidence in feedlot cattle. 466 Am. J. Vet. Res. 47, 2676-2682.

467 Martin, S.W., Meek, A.H., Davis, D.G., Johnson, J.A., Curtis, R.A., 1982. Factors associated 468 with mortality and treatment costs in feedlot calves: the Bruce County Beef Project, years 1978, 469 1979, 1980. Can. J. Comp. Med. 46, 341-349.

470 Neville, W.E., and McCormick, W.C., 1981. Performance of early and normal weaned beef

471 calves and their dams. J. Anim. Sci. 52, 715-724.

472 Ribble, C.S., Meek, A.H., Janzen, E.D., Guichon, P.T., Jim, G.K., 1995. Effect of time of year, 473 weather, and the pattern of auction market sales on fatal fibrinous pneumonia (shipping fever) in 474 calves in a large feedlot in Alberta (1985-1988). Can. J. Vet. Res. 59, 167-172. 
475 Ribble, C.S., Meek, A.H., Shoukri, M.M., Guichon, P.T., Jim, G.K., 1998. Risk factors

476 associated with fatal fibrinous pneumonia (shipping fever) in feedlot calves. In, Proc. Am.

477 Assoc. Bov. Pract. 31, 104-109.

478 Sanderson, M. W., Dargatz, D. A., Wagner, B. 2008. Risk factors for initial respiratory disease in

479 United States' feedlots based on producer-collected daily morbidity counts. Can. Vet. J. 49, 373-

$480 \quad 378$.

481 Smith, R.A., Stokka, G.L., Radostits, O.M., Griffin, D.D., 2001. Health and production

482 management in beef feedlots. In: Radostits, O.M. (Ed.), Herd Health: Food Animal Production

483 Medicine. W.B. Saunders Company, Philadelphia, pp. 581-633.

484 Swanson, J. C., Morrow-Tesch, J. 2001. Cattle transport: historical, research, and future

485 perspectives. J. Anim. Sci. 79(E. Suppl.), E109-E109.

486 Vogel, G.L., Parrott, J.C., 1994. Mortality survey in feedyards. The incidence of death from

487 digestive, respiratory and other causes in feedyards in the Great Plains. Comp. Con. Ed. Pract.

488 Vet. 16, 227-234.

489 Walter, S.D., Feinstein, A.R., Wells, C.K., 1987. Coding ordinal independent variables in

490 multiple regression analysis. Am. J. Epidemiol. 125, 319-323.

491 White, B. J., Blasi, D., Vogel, L. C., Epp, M. 2009. Associations of beef calf wellness and body

492 weight gain with internal location in a truck during transportation. J. Anim. Sci. 87, 4143-4150. 
Table 1.

\begin{tabular}{|c|c|c|c|c|c|c|c|c|c|}
\hline \multirow{2}{*}{$\begin{array}{l}\text { Arrival } \\
\text { Month }\end{array}$} & \multicolumn{9}{|c|}{ Arrival Weight in categories } \\
\hline & $182 \mathrm{~kg}$ & $182-204 \mathrm{~kg}$ & $205-227 \mathrm{~kg}$ & $228-249 \mathrm{~kg}$ & $250-271 \mathrm{~kg}$ & $272-317 \mathrm{~kg}$ & $318-340 \mathrm{~kg}$ & $341-362 \mathrm{~kg}$ & $>362 \mathrm{~kg}$ \\
\hline Jan & $\begin{array}{c}3.4 \\
(2.3-5.1)\end{array}$ & $\begin{array}{c}2.9 \\
(1.9-4.2)\end{array}$ & $\begin{array}{c}2.2 \\
(1.6-2.9)\end{array}$ & $\begin{array}{c}2.2 \\
(1.8-2.8)\end{array}$ & $\begin{array}{c}2.6 \\
(2.1-3.1)\end{array}$ & $\begin{array}{c}2.1 \\
(1.9-2.3)\end{array}$ & $\begin{array}{c}1.8 \\
(1.6-1.9)\end{array}$ & $\begin{array}{c}1.4 \\
(1.3-1.6)\end{array}$ & $\begin{array}{c}1.1 \\
(0.9-1.2)\end{array}$ \\
\hline Feb & $\begin{array}{c}1.9 \\
(0.8-4.7)\end{array}$ & $\begin{array}{c}3.9 \\
(2.8-5.5)\end{array}$ & $\begin{array}{c}2.7 \\
(1.9-3.9)\end{array}$ & $\begin{array}{c}2.2 \\
(1.7-2.9)\end{array}$ & $\begin{array}{c}3.1 \\
(2.6-3.8)\end{array}$ & $\begin{array}{c}1.8 \\
(1.6-2.0)\end{array}$ & $\begin{array}{c}1.5 \\
(1.4-1.7)\end{array}$ & $\begin{array}{c}1.2 \\
(1.1-1.4)\end{array}$ & $\begin{array}{c}0.9 \\
(0.8-1.0)\end{array}$ \\
\hline Mar & $\begin{array}{c}3.7 \\
(2.2-6.1)\end{array}$ & $\begin{array}{c}3.5 \\
(1.9-6.2)\end{array}$ & $\begin{array}{c}3.5 \\
(2.4-5.1)\end{array}$ & $\begin{array}{c}2.4 \\
(1.7-3.3)\end{array}$ & $\begin{array}{c}2.2 \\
(1.7-2.9)\end{array}$ & $\begin{array}{c}1.7 \\
(1.5-1.9)\end{array}$ & $\begin{array}{c}1.4 \\
(1.2-1.6)\end{array}$ & $\begin{array}{c}1.1 \\
(1.0-1.3)\end{array}$ & $\begin{array}{c}0.9 \\
(0.8-1.0\end{array}$ \\
\hline Apr & $\begin{array}{c}7.0 \\
(5.2-9.6)\end{array}$ & $\begin{array}{c}2.7 \\
(1.9-3.8)\end{array}$ & $\begin{array}{c}2.9 \\
(2.3-3.8)\end{array}$ & $\begin{array}{c}2.8 \\
(2.2-3.4)\end{array}$ & $\begin{array}{c}2.3 \\
(1.8-2.8)\end{array}$ & $\begin{array}{c}1.7 \\
(1.4-1.9)\end{array}$ & $\begin{array}{c}1.3 \\
(1.1-1.6)\end{array}$ & $\begin{array}{c}1.1 \\
(1.0-1.3)\end{array}$ & $\begin{array}{c}0.9 \\
(0.8-1.0)\end{array}$ \\
\hline May & $\begin{array}{c}5.3 \\
(4.5-6.3)\end{array}$ & $\begin{array}{c}5.3 \\
(4.6-6.2)\end{array}$ & $\begin{array}{c}3.7 \\
(3.2-4.2)\end{array}$ & $\begin{array}{c}2.8 \\
(2.4-3.3)\end{array}$ & $\begin{array}{c}2.7 \\
(2.3-3.1)\end{array}$ & $\begin{array}{c}1.6 \\
(1.4-1.8)\end{array}$ & $\begin{array}{c}1.3 \\
(1.2-1.5)\end{array}$ & $\begin{array}{c}1.1 \\
(0.9-1.2)\end{array}$ & $\begin{array}{c}0.9 \\
(0.8-1.0)\end{array}$ \\
\hline Jun & $\begin{array}{c}7.9 \\
(6.8-9.2)\end{array}$ & $\begin{array}{c}6.4 \\
(5.6-7.2)\end{array}$ & $\begin{array}{c}5.6 \\
(4.9-6.3)\end{array}$ & $\begin{array}{c}4.7 \\
(4.1-5.3)\end{array}$ & $\begin{array}{c}3.4 \\
(2.9-4.0)\end{array}$ & $\begin{array}{c}2.1 \\
(1.8-2.4)\end{array}$ & $\begin{array}{c}1.6 \\
(1.4-1.8)\end{array}$ & $\begin{array}{c}1.1 \\
(1.0-1.3)\end{array}$ & $\begin{array}{c}1.0 \\
(0.9-1.2)\end{array}$ \\
\hline Jul & $\begin{array}{c}7.6 \\
(6.6-8.8)\end{array}$ & $\begin{array}{c}5.8 \\
(5.1-6.7)\end{array}$ & $\begin{array}{c}5.8 \\
(5.2-6.4)\end{array}$ & $\begin{array}{c}4.4 \\
(3.8-4.9)\end{array}$ & $\begin{array}{c}4.0 \\
(3.6-4.6)\end{array}$ & $\begin{array}{c}2.5 \\
(2.3-2.8)\end{array}$ & $\begin{array}{c}1.6 \\
(1.4-1.8)\end{array}$ & $\begin{array}{c}1.3 \\
(1.1-1.4)\end{array}$ & $\begin{array}{c}0.9 \\
(0.8-1.0)\end{array}$ \\
\hline Aug & $\begin{array}{c}9.9 \\
(8.4-11.6)\end{array}$ & $\begin{array}{c}4.9 \\
(4.1-5.9)\end{array}$ & $\begin{array}{c}4.9 \\
(4.4-5.6)\end{array}$ & $\begin{array}{c}4.9 \\
(4.3-5.5)\end{array}$ & $\begin{array}{c}3.9 \\
(3.6-4.5)\end{array}$ & $\begin{array}{c}2.2 \\
(2.0-2.4)\end{array}$ & $\begin{array}{c}1.5 \\
(1.4-1.7)\end{array}$ & $\begin{array}{c}1.2 \\
(1.1-1.4)\end{array}$ & $\begin{array}{c}0.9 \\
(0.9-1.1)\end{array}$ \\
\hline Sep & $\begin{array}{c}5.0 \\
(4.1-6.1)\end{array}$ & $\begin{array}{c}5.4 \\
(4.5-6.5)\end{array}$ & $\begin{array}{c}4.8 \\
(4.2-5.4)\end{array}$ & $\begin{array}{c}4.4 \\
(3.9-4.9)\end{array}$ & $\begin{array}{c}3.8 \\
(3.4-4.2)\end{array}$ & $\begin{array}{c}2.7 \\
(2.4-2.9)\end{array}$ & $\begin{array}{c}1.7 \\
(1.6-1.9)\end{array}$ & $\begin{array}{c}1.4 \\
(1.2-1.5)\end{array}$ & $\begin{array}{c}1.0 \\
(0.9-1.2)\end{array}$ \\
\hline Oct & $\begin{array}{c}6.5 \\
(5.5-7.7)\end{array}$ & $\begin{array}{c}3.6 \\
(3.0-4.3)\end{array}$ & $\begin{array}{c}3.9 \\
(3.4-4.4)\end{array}$ & $\begin{array}{c}3.6 \\
(3.2-4.1)\end{array}$ & $\begin{array}{c}4.1 \\
(3.7-4.5)\end{array}$ & $\begin{array}{c}2.8 \\
(2.6-3.0)\end{array}$ & $\begin{array}{c}2.2 \\
(1.9-2.4)\end{array}$ & $\begin{array}{c}1.6 \\
(1.4-1.8)\end{array}$ & $\begin{array}{c}1.2 \\
(1.1-1.4)\end{array}$ \\
\hline Nov & $\begin{array}{c}6.9 \\
(5.8-8.1)\end{array}$ & $\begin{array}{c}3.9 \\
(3.2-4.6)\end{array}$ & $\begin{array}{c}4.1 \\
(3.6-4.8)\end{array}$ & $\begin{array}{c}3.9 \\
(3.4-4.4)\end{array}$ & $\begin{array}{c}2.9 \\
(2.6-3.3)\end{array}$ & $\begin{array}{c}2.7 \\
(2.5-2.9)\end{array}$ & $\begin{array}{c}2.2 \\
(1.9-2.4)\end{array}$ & $\begin{array}{c}1.6 \\
(1.4-1.8)\end{array}$ & $\begin{array}{c}1.5 \\
(1.3-1.7)\end{array}$ \\
\hline Dec & $\begin{array}{c}49 \\
(39-5.9)\end{array}$ & $\begin{array}{c}3.0 \\
(3.2-4.7)\end{array}$ & $\begin{array}{c}3.1 \\
(2.7-3.6)\end{array}$ & $\begin{array}{c}2.8 \\
(2.4-3.3)\end{array}$ & $\begin{array}{c}2.5 \\
(2.2-2.9)\end{array}$ & $\begin{array}{c}2.7 \\
(2.4-2.9)\end{array}$ & $\begin{array}{c}2.4 \\
(2.1-2.7)\end{array}$ & $\begin{array}{c}1.6 \\
(1.4-1.9)\end{array}$ & $\begin{array}{c}1.1 \\
(0.9-1.3)\end{array}$ \\
\hline
\end{tabular}

500 Table 1. Estimated probabilities (\%) and corresponding 95\% confidence intervals for combined

501 mortality and culling risk by weight class and month of feedlot arrival for cattle cohorts

502 classified as male 
Table 2.

\begin{tabular}{|c|c|c|c|c|c|c|c|c|c|}
\hline \multirow{2}{*}{$\begin{array}{l}\text { Arrival } \\
\text { Month }\end{array}$} & \multicolumn{9}{|c|}{$\begin{array}{l}\text { Arrival Weight in categories } \\
\end{array}$} \\
\hline & $<182 \mathrm{~kg}$ & $182-204 \mathrm{~kg}$ & $205-227 \mathrm{~kg}$ & $228-249 \mathrm{~kg}$ & $250-271 \mathrm{~kg}$ & $272-317 \mathrm{~kg}$ & $318-340 \mathrm{~kg}$ & $341-362 \mathrm{~kg}$ & $>362 \mathrm{lgg}$ \\
\hline Jan & $\begin{array}{c}2.4 \\
(1.5-4.0)\end{array}$ & $\begin{array}{c}3.4 \\
(2.3-5.1)\end{array}$ & $\begin{array}{c}3.0 \\
(2.4-3.8)\end{array}$ & $\begin{array}{c}2.2 \\
(1.8-2.6)\end{array}$ & $\begin{array}{c}2.3 \\
(1.9-2.0)\end{array}$ & $\begin{array}{c}2.0 \\
(1.9-2.3)\end{array}$ & $\begin{array}{c}1.6 \\
(1.4-1.8)\end{array}$ & $\begin{array}{c}1.5 \\
(1.3-1.8)\end{array}$ & $\begin{array}{c}1.8 \\
(1.4-2.3)\end{array}$ \\
\hline Feb & $\begin{array}{c}4.4 \\
(2.9-6.7)\end{array}$ & $\begin{array}{c}0.9 \\
(0.3-3.1)\end{array}$ & $\begin{array}{c}1.9 \\
(1.3-2.9)\end{array}$ & $\begin{array}{c}2.4 \\
(1.9-3.0)\end{array}$ & $\begin{array}{c}2.2 \\
(1.8-2.6)\end{array}$ & $\begin{array}{c}1.7 \\
(1.5-1.9)\end{array}$ & $\begin{array}{c}1.3 \\
(1.1-1.5)\end{array}$ & $\begin{array}{c}1.3 \\
(1.1-1.6)\end{array}$ & $\begin{array}{c}1.3 \\
(1.1-1.7)\end{array}$ \\
\hline Mar & $\begin{array}{c}7.2 \\
(5.1-10.2)\end{array}$ & $\begin{array}{c}3.0 \\
(1.7-5.5)\end{array}$ & $\begin{array}{c}3.6 \\
(2.4-5.4)\end{array}$ & $\begin{array}{c}2.4 \\
(1.8-3.2)\end{array}$ & $\begin{array}{c}2.3 \\
(1.9-2.7)\end{array}$ & $\begin{array}{c}1.7 \\
(1.5-1.9)\end{array}$ & $\begin{array}{c}1.2 \\
(1.1-1.4)\end{array}$ & $\begin{array}{c}1.0 \\
(0.9-1.2)\end{array}$ & $\begin{array}{c}1.0 \\
(0.8-1.2)\end{array}$ \\
\hline Apr & $\begin{array}{c}3.7 \\
(2.0-6.8)\end{array}$ & $\begin{array}{c}3.6 \\
(1.8-7.5)\end{array}$ & $\begin{array}{c}2.7 \\
(1.8-3.9)\end{array}$ & $\begin{array}{c}2.3 \\
(1.7-2.9)\end{array}$ & $\begin{array}{c}2.5 \\
(2.1-2.9)\end{array}$ & $\begin{array}{c}1.5 \\
(1.3-1.7)\end{array}$ & $\begin{array}{c}1.1 \\
(0.9-1.3)\end{array}$ & $\begin{array}{c}0.9 \\
(0.8-1.1)\end{array}$ & $\begin{array}{c}1.0 \\
(0.8-1.2)\end{array}$ \\
\hline May & $\begin{array}{c}5.9 \\
(4.2-8.5)\end{array}$ & $\begin{array}{c}3.4 \\
(2.5-4.6)\end{array}$ & $\begin{array}{c}3.9 \\
(3.0-4.9)\end{array}$ & $\begin{array}{c}2.9 \\
(2.3-3.7)\end{array}$ & $\begin{array}{c}2.9 \\
(2.6-3.4)\end{array}$ & $\begin{array}{c}1.5 \\
(1.3-1.7)\end{array}$ & $\begin{array}{c}1.0 \\
(0.9-1.2)\end{array}$ & $\begin{array}{c}0.9 \\
(0.8-1.2)\end{array}$ & $\begin{array}{c}0.9 \\
(0.8-1.2)\end{array}$ \\
\hline Jun & $\begin{array}{c}4.6 \\
(3.3-6.4)\end{array}$ & $\begin{array}{c}6.1 \\
(4.9-7.6)\end{array}$ & $\begin{array}{c}4.3 \\
(3.7-5.1)\end{array}$ & $\begin{array}{c}3.9 \\
(3.3-4.6)\end{array}$ & $\begin{array}{c}3.9 \\
(3.4-4.5)\end{array}$ & $\begin{array}{c}1.8 \\
(1.6-2.0)\end{array}$ & $\begin{array}{c}1.2 \\
(1.0-1.4)\end{array}$ & $\begin{array}{c}0.8 \\
(0.7-1.0)\end{array}$ & $\begin{array}{c}1.5 \\
(1.2-1.8)\end{array}$ \\
\hline Jul & $\begin{array}{c}5.9 \\
(5.0-7.0)\end{array}$ & $\begin{array}{c}6.8 \\
(5.8-7.9)\end{array}$ & $\begin{array}{c}4.9 \\
(4.4-5.6)\end{array}$ & $\begin{array}{c}4.1 \\
(3.5-4.7)\end{array}$ & $\begin{array}{c}3.6 \\
(3.2-4.1)\end{array}$ & $\begin{array}{c}2.0 \\
(1.8-2.3)\end{array}$ & $\begin{array}{c}1.4 \\
(1.2-1.6)\end{array}$ & $\begin{array}{c}0.9 \\
(0.8-1.1)\end{array}$ & $\begin{array}{c}1.3 \\
(1.1-1.6)\end{array}$ \\
\hline Aug & $\begin{array}{c}7.7 \\
(6.6-8.9)\end{array}$ & $\begin{array}{c}6.4 \\
(5.6-7.3)\end{array}$ & $\begin{array}{c}5.3 \\
(4.7-5.9)\end{array}$ & $\begin{array}{c}3.9 \\
(3.5-4.5)\end{array}$ & $\begin{array}{c}3.7 \\
(3.3-4.1)\end{array}$ & $\begin{array}{c}2.2 \\
(1.9-2.4)\end{array}$ & $\begin{array}{c}1.3 \\
(1.1-1.5)\end{array}$ & $\begin{array}{c}0.9 \\
(0.7-1.0)\end{array}$ & $\begin{array}{c}1.3 \\
(1.1-1.6)\end{array}$ \\
\hline Sep & $\begin{array}{c}7.3 \\
(5.8-9.3)\end{array}$ & $\begin{array}{c}8.1 \\
(7.1-9.2)\end{array}$ & $\begin{array}{c}5.4 \\
(4.8-5.9)\end{array}$ & $\begin{array}{c}4.0 \\
(3.6-4.5)\end{array}$ & $\begin{array}{c}3.4 \\
(3.0-3.8)\end{array}$ & $\begin{array}{c}2.2 \\
(2.0-2.5)\end{array}$ & $\begin{array}{c}1.4 \\
(1.2-1.6)\end{array}$ & $\begin{array}{c}1.1 \\
(0.9-1.3)\end{array}$ & $\begin{array}{c}1.5 \\
(1.2-1.8)\end{array}$ \\
\hline Oct & $\begin{array}{c}7.5 \\
(5.8-9.8)\end{array}$ & $\begin{array}{c}6.8 \\
(5.9-7.9)\end{array}$ & $\begin{array}{c}5.6 \\
(4.9-6.4)\end{array}$ & $\begin{array}{c}4.2 \\
(3.7-4.6)\end{array}$ & $\begin{array}{c}4.1 \\
(3.7-4.6)\end{array}$ & $\begin{array}{c}2.6 \\
(2.4-2.9)\end{array}$ & $\begin{array}{c}1.8 \\
(1.5-2.0)\end{array}$ & $\begin{array}{c}1.3 \\
(1.1-1.6)\end{array}$ & $\begin{array}{c}1.8 \\
(1.5-2.2)\end{array}$ \\
\hline Nov & $\begin{array}{c}3.0 \\
(1.8-4.9)\end{array}$ & $\begin{array}{c}3.6 \\
(2.8-4.6)\end{array}$ & $\begin{array}{c}3.8 \\
(3.1-4.6)\end{array}$ & $\begin{array}{c}3.1 \\
(2.6-3.6)\end{array}$ & $\begin{array}{c}2.9 \\
(2.6-3.3)\end{array}$ & $\begin{array}{c}2.6 \\
(2.3-2.9)\end{array}$ & $\begin{array}{c}1.8 \\
(1.6-2.2)\end{array}$ & $\begin{array}{c}1.5 \\
(1.2-1.9)\end{array}$ & $\begin{array}{c}2.1 \\
(1.7-2.7)\end{array}$ \\
\hline Dec & $\begin{array}{c}2.5 \\
(1.5-4.3)\end{array}$ & $\begin{array}{c}2.4 \\
(1.7-3.6)\end{array}$ & $\begin{array}{c}2.9 \\
(2.3-3.9)\end{array}$ & $\begin{array}{c}2.9 \\
(2.4-3.4)\end{array}$ & $\begin{array}{c}2.9 \\
(2.6-3.3)\end{array}$ & $\begin{array}{c}2.6 \\
(2.4-2.9)\end{array}$ & $\begin{array}{c}1.5 \\
(1.3-1.8)\end{array}$ & $\begin{array}{c}1.6 \\
(1.3-1.9)\end{array}$ & $\begin{array}{c}2.1 \\
(1.7-2.8)\end{array}$ \\
\hline
\end{tabular}

505 Table 2. Estimated probabilities (\%) and corresponding 95\% confidence intervals for combined

506 mortality and culling risk by weight class and month of feedlot arrival for cattle cohorts

507 classified as female

508

509

510

511

512

513

514

515

516 
Figure 1.

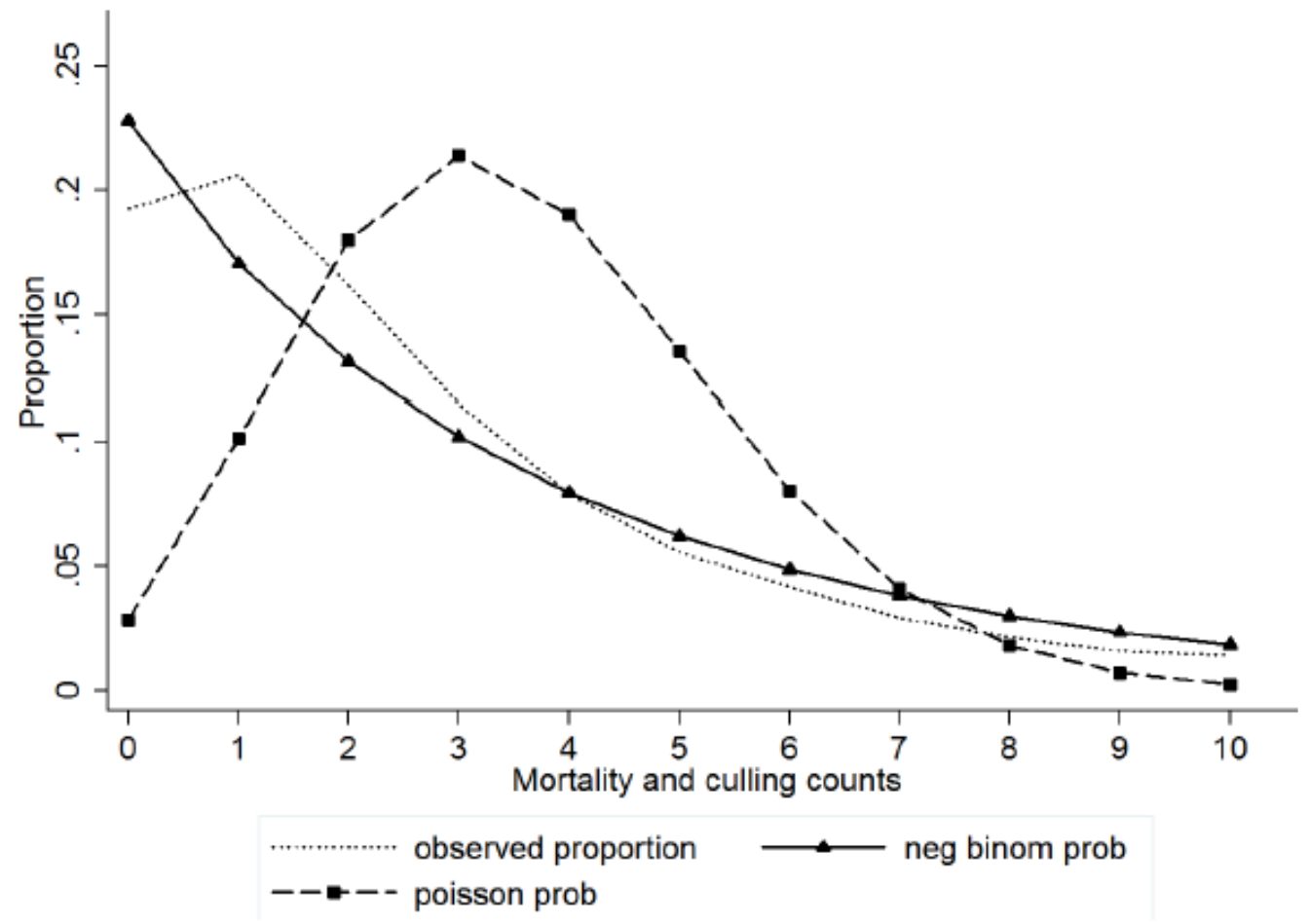

This figure graphs the distribution of the variable pertaining to combined mortality and culling counts against a Poisson (modeled with the same mean (3.53)) and negative binomial distributions (modeled with the same mean and variance ( 3.53 and 1.04 , respectively). This graph was constructed using the "nbvargy" command in STATA/MP 11.2 (StataCorp LP, College Station, TX, USA)

520 Figure 1. Probabilities for within-cohort combined mortality and culling counts based on

521 observed data, Poisson and negative binomial distributions (mean observed count = 3.53;

$522 \quad$ overdispersion parameter $=1.04)$

523 
Figure 2.
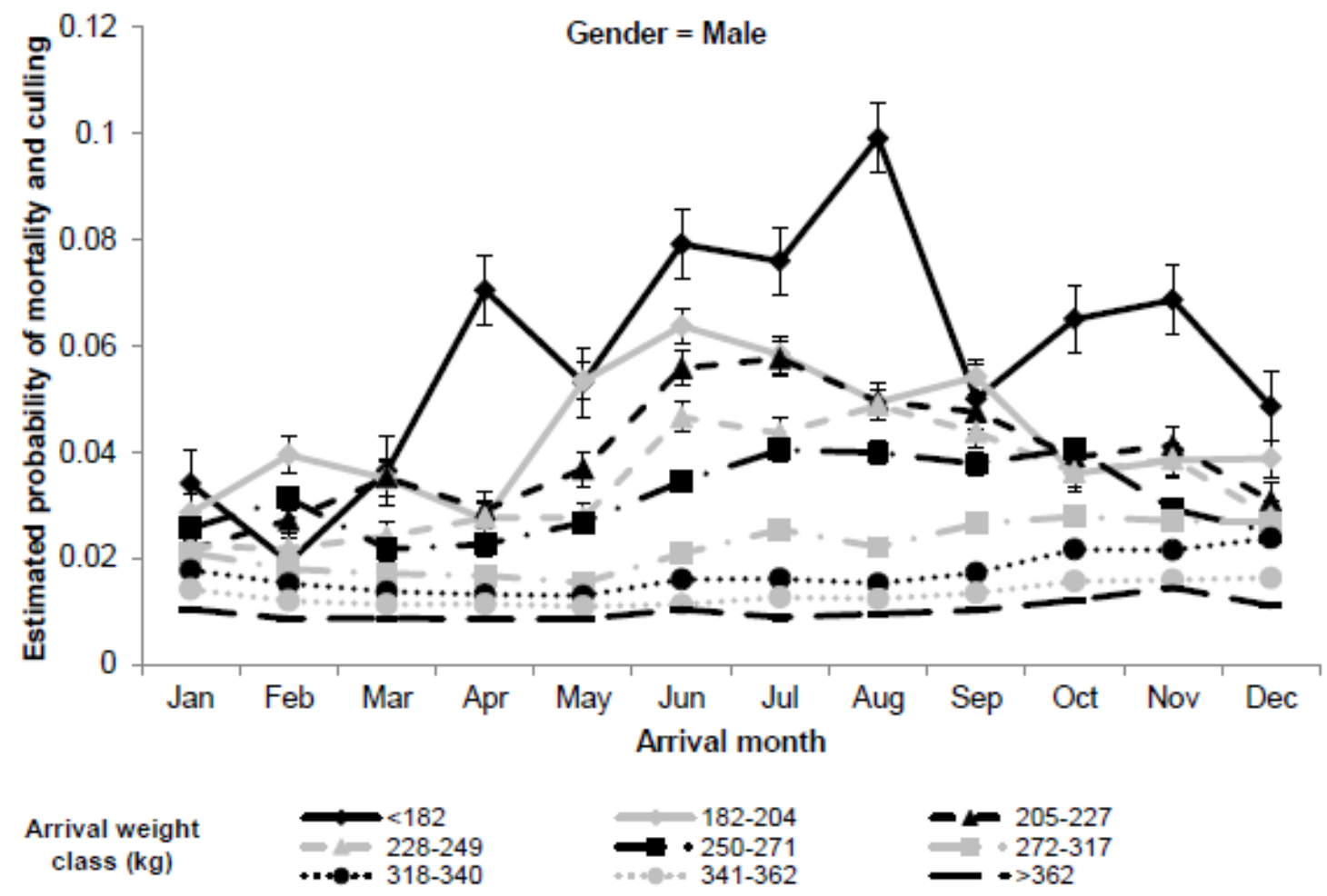

${ }^{1}$ Estimated probabilities from a generalized linear mixed model that accounted for the hierarchical and temporal structure of the data

525 Error bars indicate standard errors of least square means

526 Figure 2. Estimated probability ${ }^{1}$ for combined mortality and culling risk by gender, weight class

527 and month of feedlot arrival for cattle cohorts classified as male 
Figure 3.

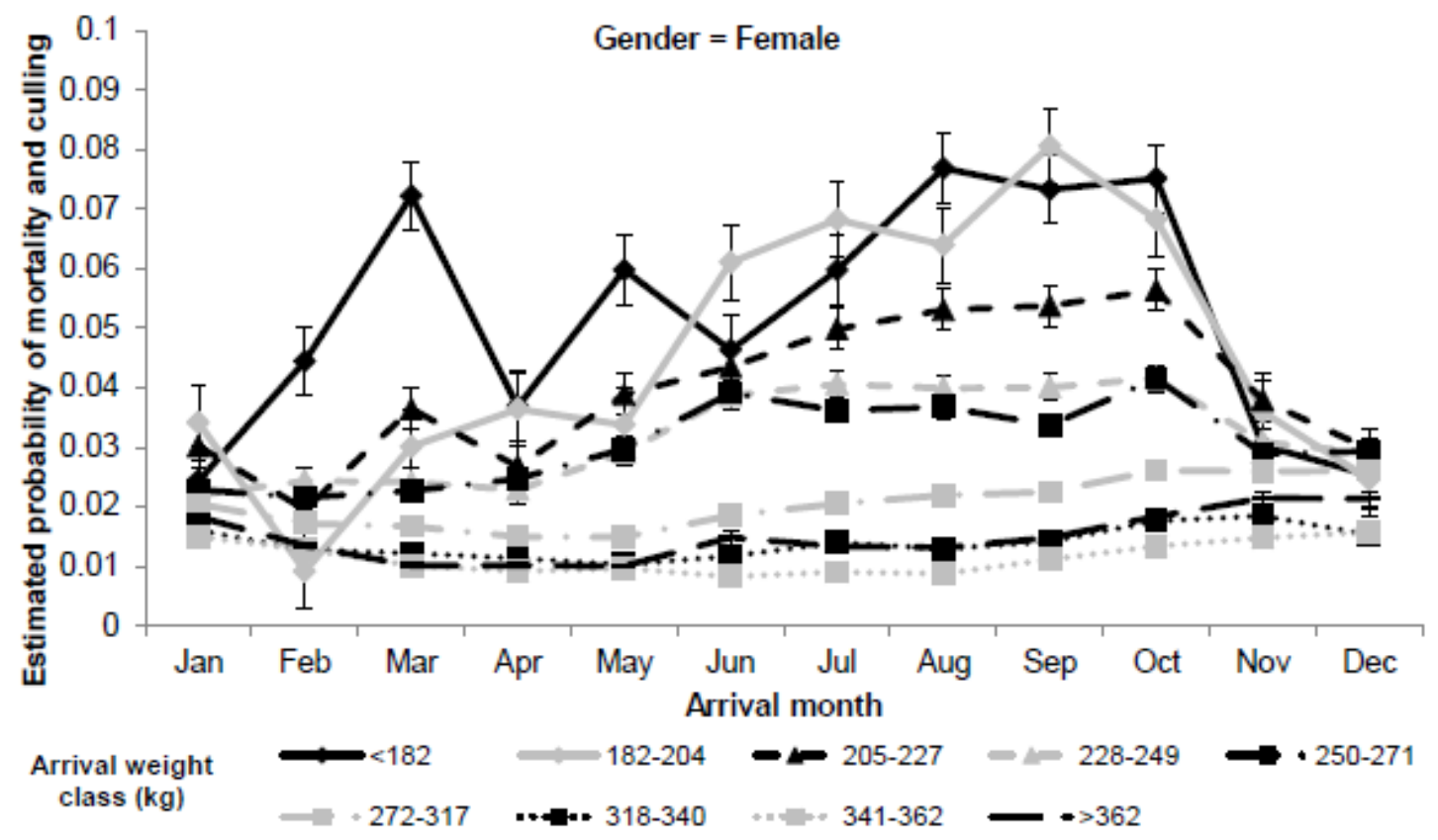

${ }^{1}$ Estimated probabilities from a generalized mixed linear model that accounted for the hierarchical and temporal structure of the data

529 Error bars indicate standard errors of least square means

530 Figure 3. Estimated probability ${ }^{1}$ for mortality and culling risk by gender, weight class and month

531 of feedlot arrival for cattle cohorts classified as female 
Figure 4 .

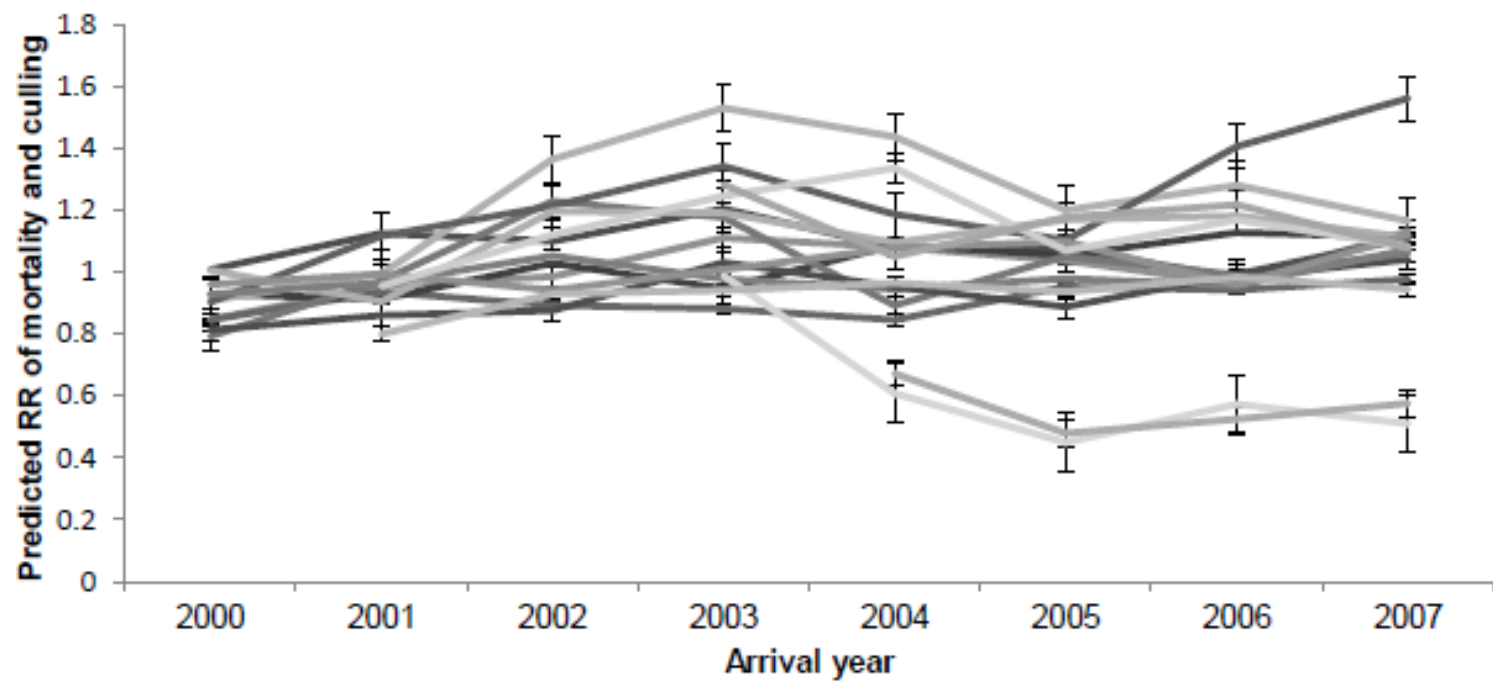

Feedlolt ID $\begin{array}{rlllllll}11 & -12 & -13 & -14 & -15 & -16 & -17 & -18 \\ 19 & -34 & -35 & -41 & -42 & 53 & -59 & -110\end{array}$

Error bars indicate standard errors of least square means

533 Data from feedlot IDs 41 and 42 were not available for years preceding 2003 and 2004, respectively

534 Figure 4. Predicted relative risk (RR) for combined mortality and culling risks for each year and

535 feedlot based on analysis of 54,406 cohorts of commercial feedlot cattle. 